\title{
INCONSISTENT USAGE OF PRIMARY AUXILIARY VERBS AMONG ESL STUDENTS AND SOLUTION: A CASE STUDY
}

\author{
M. David Raju, \\ Senior Lecturer in English, \\ Government Polytechnic, Addanki, \\ (Dept. of Technical Education, Govt. of A.P.) \\ \& Research Scholar, Ph.D (Part-Time), \\ Acharya Nagarjuna University, GUNTUR, A.P.
}

\begin{abstract}
Teaching grammar to the ESL students has been a big challenge to the English Language teachers over many years. In many of the learning styles like Grammar translation, Direct, Audio lingual, Natural, Suggestopedia, grammar was taught as a separate entity with much emphasis on rules and continuous drilling. Later, the much sought Communicative Language Teaching (CLT) mostly aimed at communicative competency, slightly ignoring grammatical competency. Most of the ESL students of Diploma in Polytechnics in Andhra Pradesh are not competent on either end. They are scared and apprehensive about learning and using correct forms of the Primary Helping Verbs i.e. 'Be, Do. Have' forms. Lack of grammatical competency slow down their fluency and they remain as wrong users of these verbs. This paper focuses on the erroneous usage of Primary Helping Verbs among the Diploma students along with general and specific reasons behind it. It also suggests that an 'Eclectic combination of Structural Approach and CLT' would serve the purpose. These ESL students who vary much in their individual learning ability look for the simple, straight, easy to remember and fool proof techniques to learn anything new. The solutions, tips suggested in this paper help the ESL students whose grammatical competency is abysmally low. To establish a basic foundation, sometimes the judicious use of mother tongue is required to evade their fears and misconception. On the whole grammar is not a packet of contents to give away, but is a skill to be acquired, practiced and attained perfection by its user.
\end{abstract}

Key words: Primary Helping Verbs, Be, Do, Have, CLT, Structure, ESL.

Instructing Grammar to the ESL students has been a big challenge to the English Language teachers over many years. The pedagogy in the early days insisted that learning a new language starts with learning of governing rules of framing sentences. In many of the previous learning styles such as Grammar translation method, Direct method, Audio lingual method, Natural method,
Suggestopedia, grammar was taught as a separate entity with much emphasis on rote learning of the rules and continuous drilling. But after 1970s, with the advent of a new learner centered approach i.e. 'Communicative Language Teaching' (CLT), the objective of achieving Communicative Competency is considered to be the highest priority. CLT has also paved the way for the motto 'fluency 
should be acquired at the cost of accuracy'. It is also apprehended that much sought CLT neglects grammatical competency. But in the actual ESL class room, even after bringing CLT techniques like Eliciting, Activities of Pair work, Group work into the class room, teachers can never avoid a special emphasis on learning grammar to maintain its accuracy. The teachers may adapt all good and feasible techniques to teach grammar, still the ESL students commit errors while using the basic Primary Helping Verbs i.e. 'be, do, have ' forms. Though the class room and real life situations aim at communicative skill, it can't be ignored that a grammatically accurate usage of English boosts up the confidence and fluency of an ESL student.

Jack C Richards of SEAMEO Regional Language Centre, Singapore in his article "30 Years of TEFL/TESL: A Personal Reflection", writes about the difference between the methods of teaching grammar before 1970 and after the adaption of Communicative Language Teaching as follows:

\begin{tabular}{|c|c|}
\hline Then & Now \\
\hline $\begin{array}{l}\text { Sentence-grammar the focus of teaching } \\
\text { Linguistic competence the goal of learning } \\
\text { Grammar often taught divorced from context } \\
\text { Accuracy-based methodology }\end{array}$ & $\begin{array}{l}\text { Accuracy and fluency of equal status } \\
\text { Grammar taught in meaningful context } \\
\text { Focus on grammar in discourse and texts } \\
\text { Communicative competence the goal of } \\
\text { learning } \\
\text { Fluency-based methodology } \\
\text { Grammar taught through tasks }\end{array}$ \\
\hline $\begin{array}{l}\text { The teachers of English } \\
\text { have many a technique to teach the } \\
\text { functioning rules of Auxiliary verbs in } \\
\text { English. The students' background } \\
\text { knowledge, interest, bent of mind to learn } \\
\text { and correct themselves and also a good } \\
\text { comprehension skill come into priority } \\
\text { while a teacher instructs grammar in the } \\
\text { class. Students of ESL usually learn their }\end{array}$ & $\begin{array}{l}\text { English grammar starting with 'Parts of } \\
\text { Speech' followed by Verbs and Tenses. } \\
\text { After some years the students are to some } \\
\text { extent able to make sentences on their } \\
\text { own. If their accuracy in using primary } \\
\text { helping verbs i.e, 'Be', 'Do', 'Have' forms } \\
\text { is tested, it is alarming. They are unable to } \\
\text { grasp the simple governing rules about } \\
\text { Primary Helping Verbs and their }\end{array}$ \\
\hline
\end{tabular}


ELK

Asia Pacific Journals

corresponding Main verbs. Most of the students who join Diploma courses in Polytechnics of Andhra Pradesh are from Telugu medium background and their understanding of the Primary Helping verbs and usage is appalling. This paper analyzes why the Telugu medium students, after studying English for many years in schools and at plus two level could not grasp the simple governing rules between Main verb forms and Primary Auxiliaries i.e. 'Be' forms, 'Do' forms \& 'Have' forms. After taking up a case study among the students of Polytechnics in A.P, it is suggested to follow an easy method of learning these Primary helping Verbs which is not new but that resembles an Eclectic combination of 'Structural Approach' and 'CLT'. It helps the ESL students understand how and when to collocate or combine a Primary Auxiliary Verb and a suitable form of main verb. Judicious use of mother tongue is required for the benefit of the students in this context to explain 'where' does a particular Primary helping verb occur independently and 'what' form of main verb collocates with it.

- The following errors are observed among the students of Diploma in Engineering who had studied English as Second language up to their tenth standard. More than
ELK Asia Pacific Journals - Special Issue ISBN: 978-81-930411-1-6

$50 \%$ of the students are just ignorant of the correct usage of these Primary Helping Verbs and habituated using them erroneously or inconsistently.

Some examples:

'I was studied in Z.P. H. School.'

'I am passed in first class.'

'We are attend the classes regularly.

\section{What could be the general reasons for these errors?}

A) Students who hail from Telugu medium have lot of influence of mother tongue. They apply same grammatical rules and usage of native language to English too.

B) They are scantily exposed to listening and speaking English environment, so they fail to grasp the unique features of English language.

C) Usually a baby learns a language in the community as he grows, by spending certain period of time involuntarily and by putting effort as in the following pyramid, where Listening as the base and takes lion's share of the time and effort followed by Speaking skill. 
ELK

\section{Asia Pacific Journals}

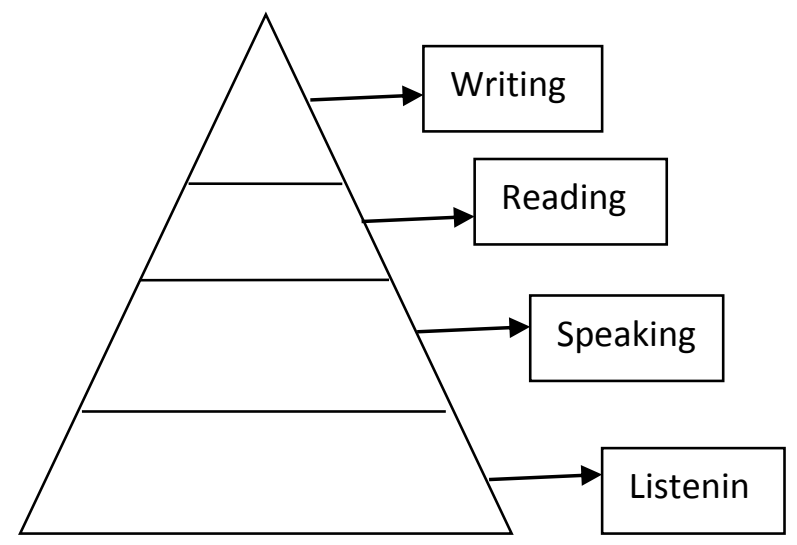

In fact the students in the ESL context limit themselves to learning literacy skills of reading and writing, ignoring listening and speaking in the target language. Even these two skills(R,W) many a time are learnt by rote learning aiming at Exams but not naturally for practical purpose. So it is evident that they start learning English language skills in the reverse order. The ESL student straight away takes a book, starts Literacy skills of Reading and Writing in the school and very scantily exposed to Listening and Speaking skills. So learning order of language skills is upside down in the ESL context like trying to make a pyramid stand on its cone. So the students fail to use these Helping verbs or any other grammatical aspect in an erroneous way in their oral or written expression.

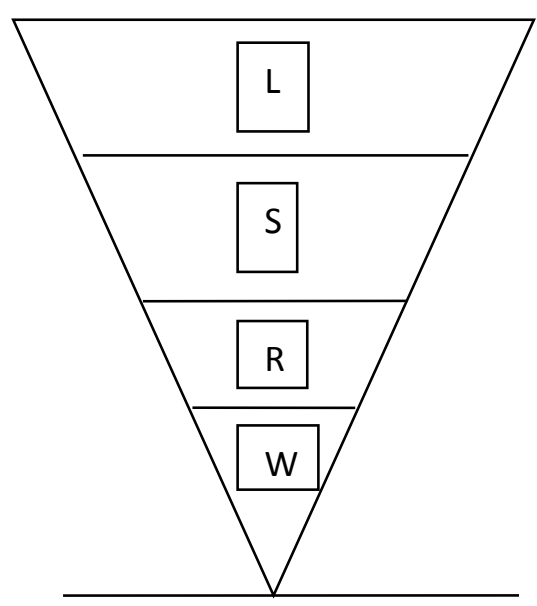

Though the student listens and reads English in the future, the wrong beginning never helps him to use the target language at ease and error free. The basic non literacy language skills of Listening and Speaking miss their emphasis in the ESL context. So even after attending many classes of English, students fail to grasp the governing rules in making a sentence.

\section{The following specific reasons are} observed for their wrong usage of these Primary helping verbs:

(i) There is no concept of Helping Verbs and Past participle in Telugu language. When they try to compare them to their mother tongue, they utterly fail to grasp about how to use them.

(ii) In Indian languages there is no clear distinction of the four aspects of a Tense as in English: simple, continuous, perfect and perfect continuous. 
Asia Pacific Journals

(iii) No idea about weak verbs that do not have difference between V2 and V3.

(Mostly 'ed' forms)

(iv) Some students with English medium back ground focus on fluency and intelligible usage of the language rather than its grammatical accuracy.

(v) Moreover, some of them depend only on set rules as they do with mathematical principles. They need exact mathematical formula like $2+2=4$, instead of 'usage' and 'meaning'. They wish that any thing new they are learning must be a well framed structure so that they can easily learn without taking pains. But learning language is other way different and we mostly depend on 'usage'. For such students it's required to reinforce grammatical accuracy regarding the use of Primary helping verbs and their corresponding main verbs with a new perspective.

\section{What do these students look for if accuracy is insisted?}

Where / in what kind of situations can we use these Primary Helping Verbs?

(They ask the teacher in Telugu, "Ee helping verbs ekkada ekkada vasthayi”?)

In how many places / contexts do they (helping verbs) occur?
What comes next to them? What is the form of main verb that follows?

Can't we use 'be 'forms and 'do' forms for same purpose? Are they really different?

How can we use 'have 'forms?

Can't we use 'is / was' in all present and 'was / were' in all past tenses?

Students with these doubts tend to use the Primary Helping verbs wrongly. Some times they accidentally use them correctly, if checked further, they use wrongly and twist the meaning, voice, even after thorough practice on Tenses. They either think that any helping verb goes with any main form of the verb and apprehend that their mistakes are negligible. So it is required to reinforce the accurate usage of these simple but very useful auxiliaries among the students.

\section{How can the teacher help these students?}

The teacher must go beyond the conventional or any established methods of teaching grammar and adapt the creative techniques based on the students' level of understanding. Some case studies may be taken up and observed and find reason for their committing mistakes. The teacher needs to stoop down to students' level and if need be, may adapt some crude methods at the early stage of teaching 


\section{Asia Pacific Journals}

these Primary helping Verbs. In Structural approach the focus is on the correct arrangement and the combination of right words at right places. In CLT, we follow PPU technique i.e. Present, Practice and Use. The teacher at the beginning presents the form of a particular grammar point. Then he makes the student practice the form and finally students are asked to use the form in their own sentences or by providing a situation.

Lynn Savage.K et al. in their book 'Grammar Matters' felt that "These days, however, more and more practitioners realize that the two orientations - grammar-based and communicative - have elements that complement each other and that, when combined, can result in an eclectic approach that is effective in teaching grammar to adult students."'(Savage KL)

Here I would like to propose an approach that resembles the Eclectic combination of CLT and Structural approach to teach these Primary Helping Verbs to the ESL students whose grammatical competency is abysmally low. In this approach the students learn two aspects of these Primary Helping verbs.

i) Independent use (as main verbs) ii) Combination with a particular form of main verb.
ELK Asia Pacific Journals - Special Issue ISBN: 978-81-930411-1-6

An idea about main verb: Before we teach the ESL students these Primary Helping Verbs, it is very important to enlighten them about the five forms of Main verbs i.e. V1, V2, V3, S-form, ing-form. ( take, took, taken, takes, taking).

I. 'Be' forms: Let's observe the usage of Primary 'be' forms.

\begin{tabular}{|l|l|l|}
\hline & Singular & Plural \\
\hline Tense & & \\
\hline Present & am, is & are \\
\hline Past & was & were \\
\hline
\end{tabular}

What are the common situations to use 'be' forms?

(a) 'be' + No Main verb (Independent use )

Here 'be' form is used itself as main verb without a Main Verb.

Ex: I am a student.

She is my friend.

There are 40 students in the class.

He was in school last year.

Those were the days of happiness.

After through practice, tell them that independent use of 'be' form has no apparent action. It is a Static verb, used to 
indicate state, existence, number, quality, position of something.

(b) 'be' + ing form ( Collocation with 'ing' form of a main verb)

Use 'be' form before 'ing' form of the Main Verb. It gives continuous action. A primary

'be' form allows a present participle( ing ) immediately after it.

Ex: I am studying well.

She was watching T.V when the phone rang.

They are shouting in the class.

We were preparing for a test last week.

( c) 'be' + V3 ( Collocation with V3

\section{form to make a Passive Voice)}

Use 'be' form before 'V3' ( Past participle) to get Passive Voice.

Ex: I am called Bunty by my friends.

The book was published.

The learner must understand the use of Passive voice structure and its purpose. Here the focus is on the object and it tells what happened to object and what the action was.

Hence, we can say Primary 'be' forms occur in three situations .i.e.;

i) Use independently,

ii) Use before 'ing' form and iii) Use before V3.
The teacher can give such tips to serve the purpose. Once the students are thorough with the structure and, they can easily understand its usage. After thorough practice of these Primary 'be' forms ,Teacher can further proceed to secondary set 'be, been, being' in the same structure based learning method followed by exemptions from the rules if any.

II. 'Have' forms: Students must understand clearly how these 'have' forms are used independently and with collocation with main verbs.

\begin{tabular}{|l|l|l|}
\hline Tense & Singular & Plural \\
\hline Present & has & have \\
\hline Past & had & had \\
\hline
\end{tabular}

(i) Use 'have' form independently as main verb which is similar in meaning ' to possess, to eat, to drink, to get', 'to experience' ..etc. $\quad$ (Have + No main Verb)

I/ We/You/They have a car.. He/she has a new cycle. I / we/ he/ she had.....

(ii) Have + V3 (Collocation with V3 form)

They have attended the class.

We had finished our exam before they gave bell. 
Let students understand difference between V2 and V3 forms of the Main Verb ,

- Tip to recognize V2 and V3 forms when both are same ( in weak or regular verbs).

I played the game. ( independent use of $\mathrm{V} 2$, it never takes any helping verb)

I have played the game ( with a helping verb, hence V3, because V3 is incomplete form and takes the help of a have form.)

The book was published, ( with a helping verb, hence V3, In passive voice V3 comes immediately after a 'be' form)

(iii) 'Have' + been + ing / V3

Collocating with been + ing / V3)

I have been learning English since my childhood. (Collocating with been + ing form)

She has been working in this office for the last four years.

They have been instructed. (Collocating with been + V3 ... in passive voice)

Let students practice these structures until they develop their own understanding. Once they are perfect in the form, they are at ease to use them in their expression.
III. 'Do' forms: Students can easily learn 'do' forms, but they wink at them. 'Do' forms appear as familiar and can be used with ease. They are too simple to pay attention and vulnerable to commit mistakes.

\begin{tabular}{|l|l|l|}
\hline \multicolumn{1}{|c|}{ Tense } & Singular & Plural \\
\hline Present & does & do \\
\hline Past & did & did \\
\hline
\end{tabular}

The teacher must be patient to make the students drill the use of 'do' forms thoroughly. Because they can understand 'do' forms easily but fail in using them.

$>$ Do forms indicate only Simple present and Simple Past tenses.

$>$ Any 'do' form takes only V1 immediately after it but not any other forms of a main verb.

Use 'do' forms to frame 'negatives' and 'questions' where there is no Helping Verb in the positive sentences.

Observe the 'do' forms table:

\begin{tabular}{|l|l|l|l|}
\hline & Positive & Negative & Question \\
\hline Simple Present & I eat early in the morning & I do not eat.... & Do I eat .......? \\
\hline Simple Present & He eats early in the morning & He does not ..... & Does he eat ......? \\
\hline
\end{tabular}




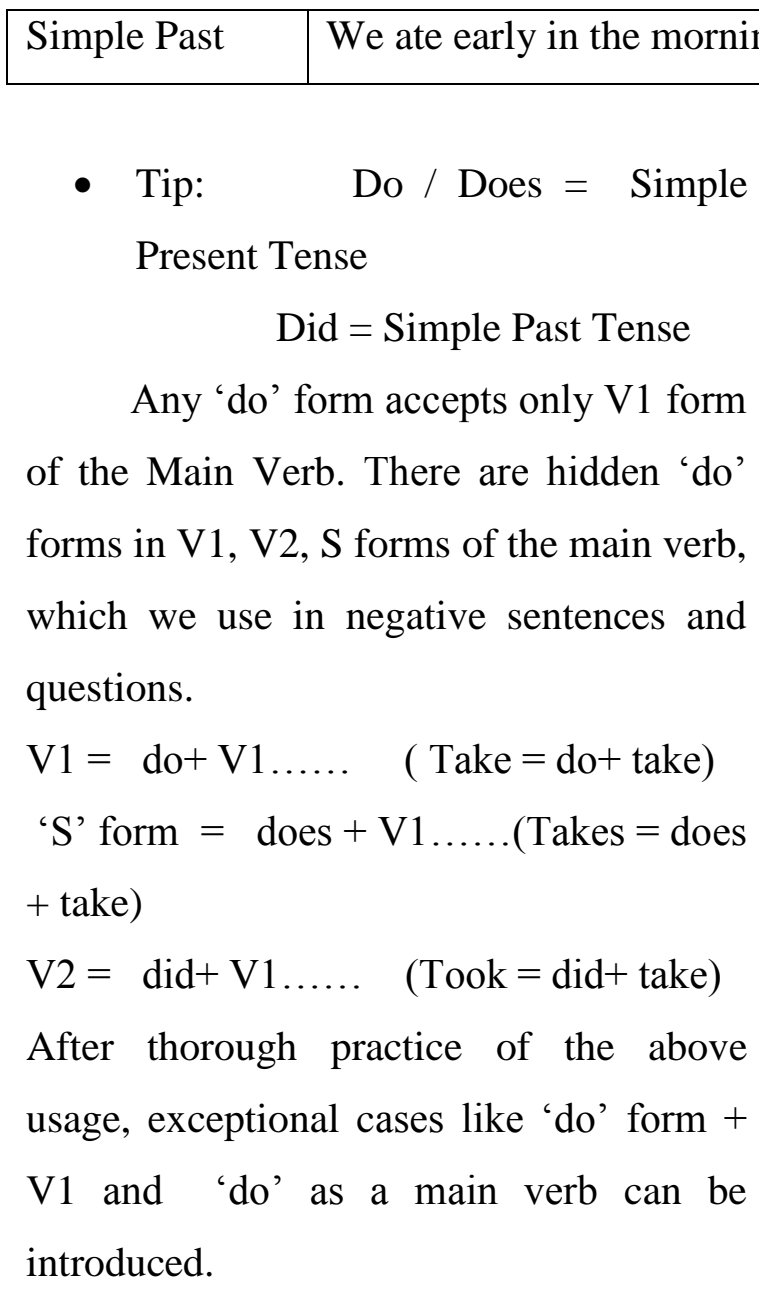

Ex: I did write well. (To ascertain) ; Please do attend the party (immense request)

What can I do for you? Will you do it now? ('do' as a main verb)

( Done is not a Helping verb. It acts only like the V3 form of a main verb)

Conclusion: ESL students look for simple, easy and straight techniques that appear like rules of thumb to learn grammar. The simple method of 'independent use and collocation use' of these Primary Helping Verbs would really
We did not eat ..... $\quad$ Did we eat....?

work as helpful techniques for the students to use error free sentences. The teacher can bring in CLT methods of PPU ( Present the form\& meaning, Practice, Use in own sentences ) and can design Pair, Group works, Exchanging the examples to make the grammar learning lively and interesting. For example a small group of 3 or 4 students can be allotted the task of writing own sentences using 'was + ing form'. Another group may be asked to write sentences using 'was+V3 form'. Later they can exchange and check the accuracy. As speaking activity, a certain situation and a particular Auxiliary verb may be written on the board and students are asked to speak as many sentences as they can. We can show some visuals like 'routine activities' of a school boy and ask them use a particular structure. Once they are thorough with the technique of 'independent use' and 'matching them with appropriate forms of main verb', their confidence level rises and they can look at grammar learning in a positive way. After getting familiarity with basic form and usage, the teacher can further proceed to explain other rules and any exceptional cases and rare examples. If the students understand in how many different structures these Primary Auxiliary Verbs 


\section{Asia Pacific Journals}

are used, it becomes easy for them to know how to use them accurately in their own expression.

Lynn Savage K.et al. in their work 'Grammar Matters' quote Richards and Rodgers, "Having reviewed the advantages and limitations of various language-teaching

methods, what can we conclude about how we should approach grammar instruction in adult ESL courses? The most sensible approach appears to be an eclectic one that combines the most effective aspects of a variety of language-teaching methodologies. (Richards and Rodgers, 2001, for their discussion of the "postmethods era."). Such an approach would include a focus on form with contextualized, communicative practice of the target structure"

Thus all the ESL students are not a single type cast to acquire grammatical proficiency in a similar way. The teacher should be resourceful, experimental based on the students level of understanding and adapt a suitable Eclectic method combining different approaches of English Language teaching to attain grammatical competency among the students.

\section{References :}

[1] Richards, Jack C and Theodore Rodgers.
ELK Asia Pacific Journals - Special Issue ISBN: 978-81-930411-1-6

Approaches and Methods in

Language Teaching (2nd

edition). New $\quad$ York:

Cambridge University

Press.2001

[2] Richards, J.C, \& Renandya, W.A (eds). Methodology in Language Teaching: An Anthology of Current Practice). Cambridge: Cambridge University Press. 2002

[3] Savage, K. Lynn et al, "Grammar Matters: Teaching Grammar in Adult ESL Programs" 2010 NY, Cambridge University Press. 2010

[4] Richards.K.C, "30 Years of TEFL/TESL: A Personal Reflection" http://community.eflclassroom .com/main/

[5] Material produced at Retraining programme to the English Lecturers in A.P. (CLT course designed by George Bishop Jr. \& others Training programme under MoU of U.S State Department of English \& Govt. of A.P.) 